\title{
AC 2010-1046: ASSESSING ELEMENTARY TEACHERS' DESIGN KNOWLEDGE BEFORE AND AFTER INTRODUCTION OF A DESIGN PROCESS MODEL
}

\section{Ming-Chien Hsu, Purdue University}

Ming-Chien is a doctoral student of engineering education and a research assistant for P-12

Engineering Research and Learning (INSPIRE) at Purdue Univeristy. She received for B.S. in Electrical Enigneering from National Chiao Tung University, Taiwan, and a MS in Electrical Engineering from Purdue University. Her current research focus is on engineering design and K-12 engineering education.

\section{Monica Cardella, Purdue University}

Monica Cardella is an Assistant Professor of Engineering Education and the Co-Director of Assessment Research for the Institute for P-12 Engineering Research and Learning (INSPIRE) at Purdue University. Prof. Cardella earned a BSc in mathematics from the University of Puget Sound and a MS and PhD in Industrial Engineering from the University of Washington. Her research interests include: K-12 engineering education, engineering design, the role of parents in engineering education, assessment, learning in informal environments, and mathematical thinking.

\section{Senay Purzer, Purdue University}

Senay Purzer is an Assistant Professor in the School of Engineering Education at Purdue University. She is also the Co-Director of Assessment Research for the Institute for P-12 Engineering Research and Learning (INSPIRE). She received a Ph.D. and a M.A in Science Education, Department of Curriculum and Instruction from Arizona State University. Her creative research focuses on collaborative learning, design \& decision-making, and the role of engineering self-efficacy on student achievement. 


\title{
Development of an Instrument to Assess Elementary Teachers' Design Process Knowledge: Findings from a Pilot Test
}

\begin{abstract}
As more states are adding engineering to their teaching and learning standards, teacher professional development activities are necessary to foster teachers' familiarity with engineering and design content. We are in the process of developing an instrument to assess teachers' knowledge of the engineering design process. This paper describes findings from one pilot test of the instrument.

The instrument (the design process knowledge task) was piloted with sixty-two elementary school teachers who attended a professional development workshop that introduced an engineering design process model that the teachers could use in their classrooms. The design process knowledge task was given to the teachers before and after the workshop. Quantitative analysis showed that there were significant differences between pre-test scores and post-test scores. We discuss the findings from this pilot study in terms of the concepts of design for which the instrument captured differences as well as the concepts where the instrument did not capture differences. The findings from the study provide insights into how the instrument can be further refined as well as insights into potential areas where teachers may need additional scaffolding in order to infuse engineering in their classrooms.
\end{abstract}

\section{Introduction}

Engineering design has been identified as one of the key concepts to be learned at the K-12 level ${ }^{1}$. Recent studies have provided evidence that learning engineering content, especially engineering design, can motivate students and facilitate the learning of science ${ }^{2}$. One of the frameworks that researchers use to understand design is to characterize the process of design ${ }^{3,4}$. New reports on engineering education have also recognized the design process as an important part of K-12 engineering learning 5 .

Consequently, more and more states are adding engineering content, including design, as part of their K-12 teaching and learning standards. Efforts to include engineering at the K-12 level need to include teachers as one of the primary agents of engineering education. However, studies like the one conducted by Yasar et al. pointed out that K-12 teachers exhibited low familiarity with design and engineering content ${ }^{6}$, which pointed out the need for teacher preparation in the field. There is a need to explore ways to assess teachers' familiarity with engineering and design content in order to i) understand teachers' initial understating of engineering and design and ii) make suggestions on the scaffolding we can give to teachers. We describe in this paper the efforts we made to develop an instrument that measures teachers' knowledge about the engineering design process as well as some findings from a pilot study of the instrument.

\section{Method}

In order to assess elementary school teachers' understanding of the engineering design process, we are in the process of developing an instrument based on an existing instrument used to 
measure college students' understanding of the engineering design process. Bailey and his colleagues developed, implemented, revised and tested a design task that prompts students to critique someone else's design process, as it is documented in a Gantt chart with a brief verbal description ${ }^{7}$. In addition to administering the task to many different populations of engineering students, Bailey has also administered the task to practicing engineers in order to further validate the instrument ${ }^{8}$.

We have changed the task description to ask the teachers to examine a students' design process as depicted in Figure 1. The task description asked the teachers to "Imagine that you asked your students to design a container to keep an egg safe during an egg drop contest. Now imagine that we were able to capture one of the students' design process and create the following table showing the different activities that she/he engaged in, how much time was spent on each activity as well as the student's sequence of events." and comment on 1) what is good about the depicted process and 2) how the process can be improved.

\begin{tabular}{|l|l|l|l|l|l|l|l|l|l|l|l|l|l|l|}
\hline & \multicolumn{7}{|c|}{ Time (e.g. hour 1, hour 2...) } \\
\hline Activity: & 1 & 2 & 3 & 4 & 5 & 6 & 7 & 8 & 9 & 10 & 11 & 12 & 13 & 14 \\
\hline $\begin{array}{l}\text { Create many different concepts for the container } \\
\text { through brainstorming }\end{array}$ & & & & & & & & & & & & & & \\
\hline Choose the most promising concepts & & & & & & & & & & & & & & \\
\hline $\begin{array}{l}\text { Decide what materials are needed for the } \\
\text { container }\end{array}$ & & & & & & & & & & & & & \\
\hline Create a test-version of the container & & & & & & & & & & & & & & \\
\hline Test the test-version of the container & & & & & & & & & & & & & & \\
\hline $\begin{array}{l}\text { Make changes to the container based on test } \\
\text { results }\end{array}$ & & & & & & & & & & & & & & \\
\hline Build the final version of the container & & & & & & & & & & & \\
\hline Write up a summary describing the project & & & & & & & & & & & & & & \\
\hline
\end{tabular}

Figure 1. The design process the teachers were asked to comment on

As a part of the validation process, we pilot tested the instrument with elementary teachers voluntarily participating in a summer five-day professional development workshop that focused on integrating engineering content into mathematics and science curriculum. Among various activities that the teachers took part in, such as demonstration of what different types of engineers do, they were introduced to the engineering process model from the "Engineering is Elementary" units developed by the Boston Museum of Science ${ }^{9}$. The teachers participated in design activities and discussions based on the model throughout the workshop, including an activity helping teachers to map their normal activities to the design process as well as two complete Engineering is Elementary units. For example, the teachers worked in teams to design sails for sailboats as a demonstration of what they could incorporate in their own classrooms. The learning goals of such activity were aligned with science learning standards for the teachers' specific states, such as keeping a notebook that includes observations, investigating and describing how moving air and water can be used to run machines, etc. During the activity, the teachers were prompted to adhere to the design process as presented in Figure 2. 
Note that besides the concepts of ask, imagine, plan, create, and improve as presented in the design process model in the "Engineering is Elementary" unit, we also added test, time and document in the process. The test concept is an implicit activity that links create and improveafter a design is created, it can be tested to identify opportunities for improvement. This testing process is included in the Engineering is Elementary units, although it does not appear in their diagram. The time concept came from Bailey's original rubric. As teachers need to design lesson plans to carry out design process and also monitor students' process, we choose to include it in our rubrics. The document aspect was also included in Bailey's original rubrics. It is relevant to the elementary context since documenting process and observations are prevalent in the science learning standards in many states. An additional reason for including the document concept is that the teachers were encouraged multiple times throughout the five-day workshop to document their ideas and activities in their "engineering notebooks." At the beginning of the workshop, the facilitator also explicitly discussed the importance of documentation in engineering practice.

\section{Engineering Design Process}

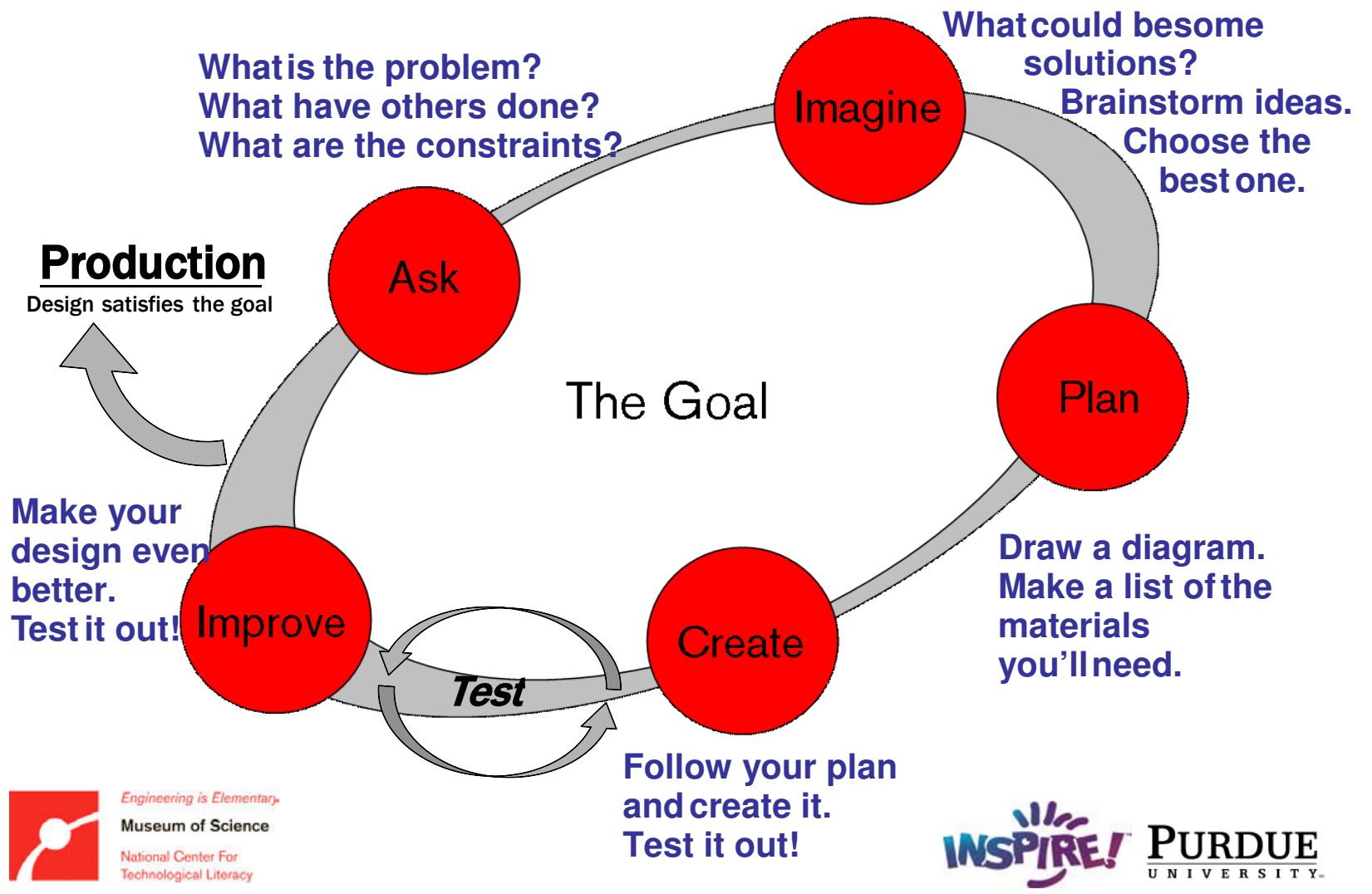

Figure 2. The engineering design process model the teachers adhered to in the professional development workshop

Our specific research question related to this pilot test were:

- Will the Elementary Teacher version of the Design Process Knowledge Task capture changes in Elementary Teachers' understanding of the 
engineering design process after a week-long teacher professional development workshop?

This research question is important in the context of instrument development because one criterion of a successful assessment instrument is that it should be able to capture pre-/postintervention differences. To address this question, we gave the task to a group of 62 elementary teachers who participated in the week-long workshop. The participants were given the task as described above on a web-based interface before the start of the workshop and right after the workshop.

The participants' written responses were qualitatively analyzed according to eight aspects of design process. The pre-test and post-test qualitative responses were coded with the eight aspects associated with the design process model as described above. Quantitatively, we chose to assess the responses dichotomously. The teachers' responses either pertain to an aspect or it does not. Table 1 summarizes the rubrics used to evaluate the teachers' responses.

Table 1. Assessment rubrics

\begin{tabular}{|c|c|c|c|c|c|c|c|c|}
\hline $\begin{array}{c}\text { Design } \\
\text { Concept }\end{array}$ & Ask & Imagine & Plan & Create & Test & Improve & Time & Document \\
\hline $\begin{array}{c}\text { Present in } \\
\text { response? }\end{array}$ & $\mathrm{Y} / \mathrm{N}$ & $\mathrm{Y} / \mathrm{N}$ & $\mathrm{Y} / \mathrm{N}$ & $\mathrm{Y} / \mathrm{N}$ & $\mathrm{Y} / \mathrm{N}$ & $\mathrm{Y} / \mathrm{N}$ & $\mathrm{Y} / \mathrm{N}$ & $\mathrm{Y} / \mathrm{N}$ \\
\hline
\end{tabular}

To analyze the quantitative data for pre/post differences, we chose to perform non-parametric tests since the data violated assumptions of parametric tests. All statistical tests were performed using SPSS statistical package version 17. To compare the responses of the pre-test and the posttest, we performed McNemar test on the paired two-level data. Also, we calculated the number of design aspects in each teacher's response. The sum of the number of concepts was counted as each teacher's total design process score. Each teacher had a pre-score and a post-score. The highest possible score was 8 points. We then compared the pre-scores to post-scores using Wilcoxon signed rank test. Effect size was calculated where appropriate.

\section{Results}

According to one-tailed Wilcoxon signed rank test, the post-score had a significantly higher median $(\mathrm{Mdn}=3)$ than the pre-score $(\mathrm{Mdn}=2), z=-3.20, p<0.01, r=-0.29$. Please refer to Table 2 for descriptive statistics of the pre-score and post-score.

Table 2. Mean and standard deviation of pre-score and post score.

\begin{tabular}{r|cc} 
& \multicolumn{2}{|c}{$(\mathrm{N}=62)$} \\
& Mean & SD \\
\hline pre-score & 2.27 & 1.45 \\
post-score & 3.15 & 1.51
\end{tabular}


We further looked into which aspects of the design process improved after the workshop. The Mcnemar test using binomial distribution at a one-tailed significance level of 0.05 showed a significant increase in the number of participants mentioning the aspects of test, build, and time in post-test as compared to pre-test. Table 3 summarizes the proportion of people mentioning each concept in the pre-test and post-test.

Table 3. Proportions of participants mentioning each aspect of the design process in the pre-test and post-test. An asterisk (*) indicates that the particular concept is significant in the McNemar test.

\begin{tabular}{rrr} 
& Proportions & $(\mathrm{N}=62)$ \\
\cline { 2 - 3 } & pre-test & post-test \\
\hline Ask & $3.23 \%$ & $6.45 \%$ \\
Imagine & $22.58 \%$ & $25.81 \%$ \\
Plan & $14.52 \%$ & $22.58 \%$ \\
Test* $^{*}$ & $41.94 \%$ & $61.29 \%$ \\
Create* $^{*}$ & $19.35 \%$ & $41.94 \%$ \\
Improve & $37.10 \%$ & $53.23 \%$ \\
Time* $^{*}$ & $54.84 \%$ & $70.97 \%$ \\
Document & $33.87 \%$ & $32.26 \%$
\end{tabular}

Therefore, the instrument captured differences between the pre-/post- workshop responses for Test, Create and Time as well as total score (overall number of concepts addressed). The instrument did not capture statistically significant pre/post differences for Ask, Imagine, Plan, Improve and Document.

\section{Discussions and Implications}

In this section, we provide some discussion of the pre-/post- workshop differences that were captured by the instrument. However, we must consider these findings to be very tentative, as the instrument is still under development. The remainder of this section focuses on implications for the instrument.

\section{Discussion of the pilot results}

According to the Wilcoxon signed rank test, there was a significant difference between postscore and pre-score. The aspects that improved the most after the workshop were test, build, and time. In the activities the teachers did during the workshop, although all aspects of the design process were emphasized, the teachers spent most time building prototypes and testing them. This could be a reason of why those two aspects improved significantly after the workshop. Also, as the teachers were involved in the activities in the workshop, they were concerned about the project management and time management aspect of incorporating engineering in their classrooms. Their attention to the time aspect of the design process might be a result of their attention to the applicability of design activities in the classrooms.

Ask is the concept least frequently mentioned. Most problems in the science and mathematics curriculum are well-defined, and the teachers might be accustomed to teaching and working with 
well-defined problems. Ask refers to gathering information about the design problem and design task. It corresponds to the problem scoping aspect of design in which designers have to explore the problem space, which might be ill-defined. That the elementary teachers addressed "Ask" infrequently is consistent with studies of college-level engineering students who spend little time in problem scoping activities. ${ }^{3}$ However, ill-defined design problems can provide K-12 students opportunities to deal with problems that are closer to real-life and thus introducing ill-defined problems can teach the abilities to gather information, assess situations, and scope the problem. However, in order to lead classroom activities on problem scoping, teachers have to realize the importance of it first. Therefore it is important to: i) ensure that a design process knowledge task is able to accurately assess teachers' understanding of Ask design activities and ii) conduct further research with a finalized instrument to see if there is truly gap in teachers' understanding of the Ask concept. If this finding is persistent, then it will be important to scaffold activities in professional development workshops so that teachers can both realize the importance of Ask activities and develop skills associated with these activities.

One way to help teachers (as well as students) develop this skill is through in depth conversations about design solutions (e.g. "for this solution, what problem is being addressed?") and by stopping design activities to ask each teacher (or student) to articulate the problem that they are currently addressing. Alternatively, teachers (and students) can be given a design scenario and then prompted to list all of the possible problems one might address as well as all of the information that would be needed to address those problems. Finally, we might consider tasks such as the Midwest Floods Task ${ }^{10,}$ which was developed to assess college students' problem scoping abilities. Tasks like this might be used both as instructional activities or as another means for assessing problem scoping ability.

\section{$\underline{\text { Implications for the instrument }}$}

The significant difference in total score suggested that the instrument were able to reflect the teachers' gained experience during the workshop. To further validate the instrument, we plan to have a second coder apply the rubric to the data and have another group of teachers who do not go through professional development workshop perform the task twice within the time frame of a week.

Although the total scores showed significant differences, the effect size represented only a small to medium difference. Because the difference is small, it is possible that the instrument needs to be refined. It could be that the task itself needs to be refined, although it is probably more likely that we need to revise the rubric so that it captures different levels of proficiency. However, there are two other possible explanations: 1) the teachers' design process knowledge did not change dramatically because the professional development was not long enough or 2) the teachers did not fully engage in the task at the end of the workshop because they had just finished an intense, week-long professional development workshop. At this time, we believe that the possibility that the rubric cannot fully capture changes in design process knowledge is worth further consideration.

As reported in this paper, as a first step to explore ways to assess elementary teachers' knowledge on design process, we adopted a set of rubrics depending on whether the teachers 
mentioned an aspect of the process or not. What the rubrics we used did not capture is the how differently the teachers reasoned the process qualitatively. We will develop in the future a set of rubrics that maps to different levels of reasoning as documented on design process learning literature.

Ultimately, the instrument can be used in teacher professional development workshops to answer questions such as i) which aspects of the design process should be emphasized in the workshop according to the pre-test results, and ii) if instruction need to be tweaked according to the pre-test and post-test comparison. Because the data reported in this paper were gathered as part of a pilot study, we must consider the findings to be very preliminary and tentative, yet worthy of future follow-up study.

\section{Acknowledgement}

This work was made possible by a grant from the National Science Foundation (DRL 0822261). Any opinions, findings, and conclusions or recommendations expressed in this material are those of the author and do not necessarily reflect the views of the National Science Foundation.

Additionally, we would like to thank Heidi Diefes-Dux and Macon Beck for their help with administering the pilot of the instrument. We would also like to thank all of the teachers who agreed to participate in the workshop as well as the research activities.

\section{Bibliography}

1. National Committee on Science Education Standards and Assessment; National Research Council, National Science Standards. The National Academies Press: Washington, DC, 1996.

2. Mehalik, M. M.; Doppelt, Y.; Schunn, C. D., Middle-school science through design-based learning versus scripted inquiry: Better overall science concept learning and equity gap reduction. Journal of Engineering Education 2008, 97, (1), 71-85.

3. Atman, C.; Chimka, J.; Bursic, K.; Nachtmann, H., A comparison of freshman and senior engineering design processes. Design Studies 1999, 20, (2), 131-152.

4. Atman, C.; Bursic, K., Verbal protocol analysis as a method to document engineering student design processes. Journal of Engineering Education 1998, 87, (2), 121-132.

5. Committee on K 12 Engineering Education; National Academy of Engineering and National Research Council, Engineering in K-12 Education: Understanding the Status and Improving the Prospects. The National Academies Press: Washington, D.C., 2009.

6. Yasar, S.; Baker, D.; Robinson-Kurpius, S.; Krause, S.; Roberts, C., Development of a survey to assess K12 teachers' perceptions of engineers and familiarity with teaching design, engineering, technology. Journal of Engineering Education 2006, 95, (3), 205-216.

7. Bailey, R.; Szabo, Z., Assessing engineering design process knowledge. International Journal of Engineering Education 2006, 22, (3), 508-518.

8. Bailey, R., Comparative study of undergraduate and practicing engineer knowledge of the roles of problem definition and idea generation in design. In International Journal of Engineering Education, 2008, 24, 226-233.

9. Cunningham, C. M.; Hester, K. In Engineering is elementary: An engineering and technology curriculum for children, American Society of Engineering Education Annual Meeting, 2007, Honolulu, HI.

10. Kilgore, D., C.J. Atman, K. Yasuhara, T.J. Barker, and A. Morozov," Considering Context: A Study of First-Year Engineering Students", Journal of Engineering Education, 2007, 96, (4), 321-334. 